\title{
A new best practice approach for mine closure in the tropics
}

\author{
H.D. Smith Northern Land Council, Australia
}

\begin{abstract}
This paper considers how mine closure is approached in the tropical environment. It ties together a range of technical and social topics, including: governance and regulation; stakeholder input; mining economics; long-term social economics; health impacts; development of specific closure criteria for a number of different types of mines and land management practices. It highlights what can and often will go wrong where standard mine practices are applied to the tropics and, drawing on specific examples, looks at the positive and negative outcomes from attempts at mine closure in Australia's Northern Territory during the late 20th and early 21 st centuries. From these, a new paradigm is synthesised and offered as an improved "best practice".
\end{abstract}

\section{Introduction}

This paper seeks to further investigate and promote the application of traditional ecological knowledge and land management practices to mine closure. Through this it seeks to further refine what is considered current best practice by governments, the mining industry and regulators, while proposing systems of management that can also contribute to sustainable cultural and economic well-being of indigenous people through the provision of meaningful employment and satisfactory long-term environmental outcomes. Successful outcomes carry with them the potential to contribute significantly to continual improvement, not only within the mining sector but also to the dire social situations that many Aboriginal people face today.

The mining industry in Australia takes its guidance from many high-level codes and standards designed to describe and promote best practice in sustainability, environmental management, and mine closure (ANZEC/MCA, 2000; Environment Australia, 2002; DITR, 2006). These documents provide a number of objectives, a common one which is to enable all stakeholders to have their interests considered during the mine closure process. In practice however, few companies consider Aboriginal people or their viewpoint as being distinct from the wider community. This is despite meaningful participation by Aboriginal peoples and the use of traditional and local knowledge constituting an important part of the Whitehorse Initiative (WMI, 1994), around which these documents are commonly built.

A second common objective entails application of risk-based assessments to mine closure planning during the pre-mining feasibility stage so that both long-term cost and uncertainty to the company, but not necessarily affected communities are reduced. These assessments typically consider risk to the environment and project economics, but do not adequately translate them into risks to either health or the natural resource based economics of affected Aboriginal groups. Improved outcomes could be achieved if cultural landscaping and assessments based upon cultural consequences are used.

It is this - the failure to fully appreciate indigenous economic use of the natural environment - that means the full and long-term costs of any mining venture to community sustainability is rarely determined. This is reflected in significant concern seen in remote parts of tropical Australia, particularly where low cost rehabilitation options are being favoured by mining companies leaving under-resourced Aboriginal communities to face mining legacies that have the potential to severely affect their health; and impact upon their cultural practices and socio-economic well-being.

In the context of sustainable mine closure, best practice planning must consider three critical factors all of which are of vital interest to Aboriginal communities. These are: access to the post-mining landscape; its management; and management of long-term contamination of water supplies. This paper therefore seeks to examine these key aspects of closure plans and relate them to Aboriginal interests; thereby synthesising a new paradigm that leads to quality outcomes for future generations of Aboriginal people. 


\section{Methodology}

A review of publicly available closure plans, environmental reports and scientific literature related to ten major mines (Table 1) in the tropical region of Australia's Northern Territory was done. Physical inspections were made of areas rehabilitated or undergoing rehabilitation at six of these mines: Rio-Tinto Alcan Gove, Ranger, Rum Jungle, Nabarlek, Woodcutters and Redbank. Participative dialogue with customary (or traditional) Aboriginal owners whose land is affected by each mine followed and was used to determine how they consider their cultural and socio-economic well being has been impacted. Consultation with respect to Rum Jungle, Ranger and Woodcutter's Mines is a continuing process.

Cultural landscapes were then developed for two mines - Ranger and Rio Tinto Alcan Gove. The information received for each was tabulated for storage into database systems and transcribed onto maps for visual reference. A typical map, showing the pre-mining patterns of land and natural resource use at Rio Tinto Alcan Gove is shown in Figure 1, while that for Ranger has previously been reported elsewhere (Smith, 2009).

\section{$3 \quad$ Results and discussion}

\subsection{Cultural landscaping and development of closure criteria}

Cultural landscapes reflect the confluence of man's interaction with the natural environment including economic values and patterns of use of natural resources as reflected by each Aboriginal group's unique sets of Traditional Ecological Knowledge. A clearer understanding of traditional socio-economics and anticipated impacts upon them can be developed if this tool is used during baseline social impact assessments prior to mine development, throughout operations and during closure. Unfortunately cultural landscaping is rarely done and its absence prevents an accurate determination of whether or not a proposed mine will ultimately be economically beneficial or detrimental to Aboriginal people.

In the example provided in Figure 1, it was not possible to quantify a monetary value for the past, present or future amounts of natural resources lost because the landscaping work was undertaken retrospectively and the abundance of each natural resource type utilised was never recorded. Anecdotal evidence indicates that prior to construction of the red mud waste dumps; the area was rich in resources and a favoured hunting ground for local Aboriginal people. Closure of this mine is not expected for at least another 40 years and over this period of time red mud waste deposition is expected to consume more of the land to the east and continue to undermine the land's economic value and productivity. The red mud waste dumps are expected to become a permanent feature of the landscape, meaning that the amount of compensation paid by way of royalties may not be adequate recompense for future generations and that one principal of sustainability that of intergenerational equity - cannot be maintained.

Cultural landscaping has another important role because it can be used to assist with the development of closure criteria relevant to Aboriginal socio-economics and land management practices employed in the postclosure environment - even though this may no longer be possible at Rio Tinto Alcan Gove. As a general principle, criteria developed in response to cultural landscaping are sensitive to Aboriginal cultural and socio-economic needs, but must also be scientifically robust if they are to have enduring value

Links between scientific and culturally based closure criteria have been established (Smith, 2008; Smith, 2009) and this approach should be utilised in conjunction with cultural landscaping to provide a high-level direction to the closure process. For it to be effective, Aboriginal people must be involved at all stages of closure criteria development. Although Aboriginal input is now being sought as a key part of the closure process for the Ranger Uranium Mine, the continued reliance on and preference for the use of analogue sites to direct closure indicates an entrenched resistance to the application of Traditional Ecological Knowledge and the Aboriginal viewpoint exists. This is further evidenced at major mines such as Rio Tinto Alcan Gove and McArthur River, where engagement by the mining companies of Aboriginal people and application of their Traditional Ecological Knowledge in closure planning simply does not exist. 


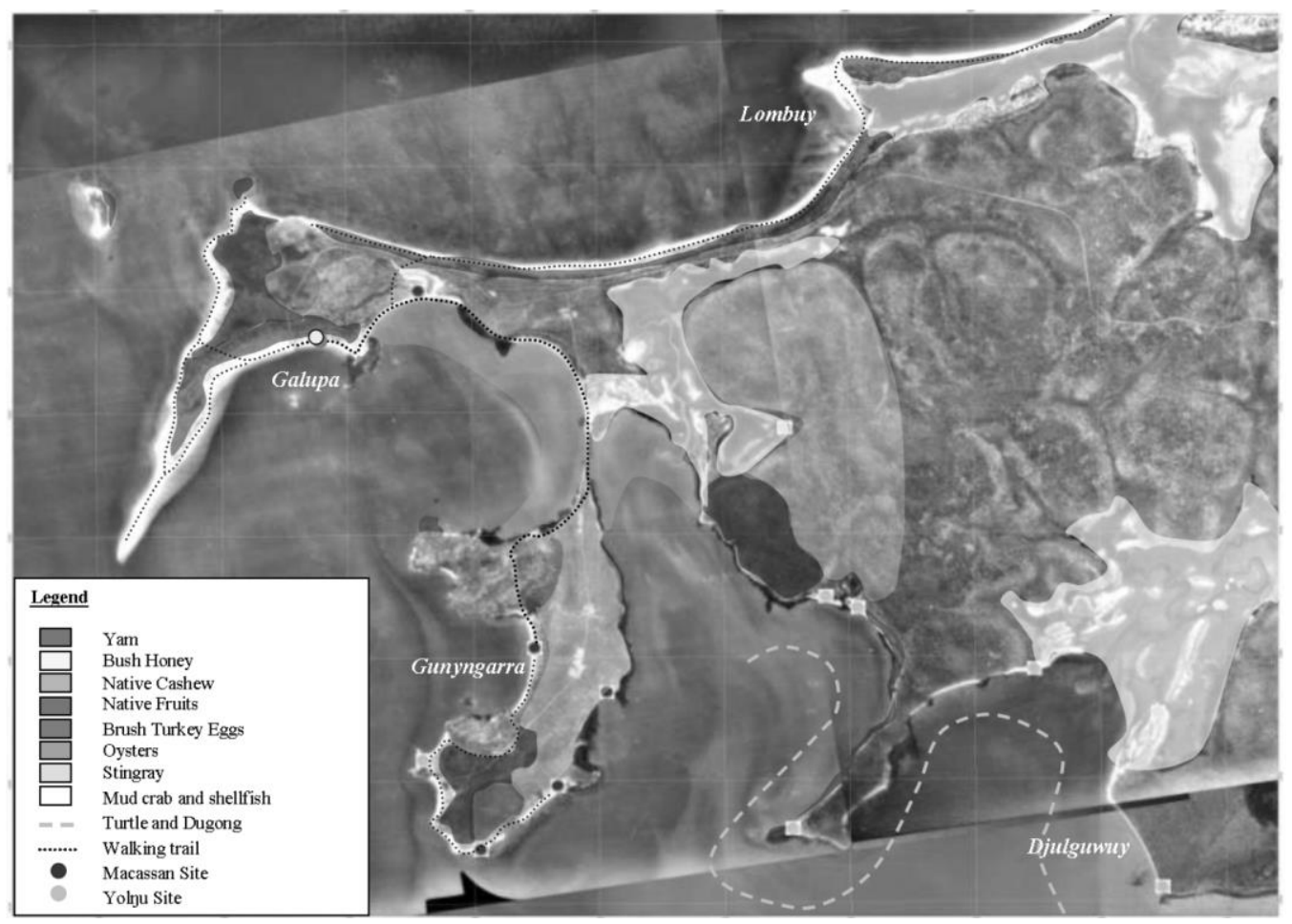

Figure 1 Cultural landscape demonstrating natural resource use prior to construction of an alumina refinery on the Gove Peninsula

\subsection{Tailings and waste rock management}

The current state of rehabilitation at many mines makes it difficult to apply Aboriginal land management practices and closure criteria drawn from pre-mining cultural landscape. Across Australia, post mining landscapes are commonly characterised by remnant infrastructure; pit voids; and large waste rock stockpiles and tailings dumps - all of which limit future productive use of previously mined land. Rehabilitation of the surface structures usually entails drainage followed by placement of soil covers and vegetation, while pit voids are commonly left to fill with water. Current regulatory practices deem this to be acceptable and sufficient for long-term environmental protection, even though it is not sustainable in the tropics, often leads to serious environmental impacts such as acid mine drainage; and does not provide any significant long-term benefit for future generations.

There is ample evidence that heavy rainfall and extreme weather events associated with the tropical climate coupled with inadequate water management and rehabilitation practices have resulted in serious environmental concerns in the Northern Territory. Acid mine and metalliferous drainage is observed at Mount Todd, Rum Jungle, Redbank, and McArthur River, while caustic drainage is seen at Rio-Tinto Alcan Gove. These impacts are a direct result of seepage from or erosion and weathering of "rehabilitated" tailings dumps and waste rock stockpiles and have led to detrimental impacts on traditional food sources as well as the wider environment. When the possibility of widespread release of radioactive material from surface storage of radioactive tailings is also considered there is a clear indication that best practice tailings management must now evolve from the traditional paradigm of surface-based tailings storage facilities and waste rock stockpiles (Mudd et al., 2011). One alternative is to return tailings and waste rock to the pit, which would greatly diminish the prospect of erosion driven impacts, such as the transport of acid mine and metalliferous drainage into nearby waterways.

Dealing with radioactive tailings found strewn across areas of the southern reaches of Kakadu National Park from mines in the 1950s and 1960s required construction of a specialised subterranean facility (Reszat et al., 2009). At Ranger, the Commonwealth Government now mandates in-pit storage of tailings and waste rock, a practice previously undertaken at the Nabarlek Uranium mine, although on a much smaller scale. At Nabarlek impacts still occur via plumes of contaminated groundwater generated by uncontrolled seepage of 
tailings porewater from the backfilled pit. If this is to be prevented at larger mines like Ranger, sophisticated systems of drainage will be required. Dealing with erosion and caustic drainage at Rio Tinto Alcan presents a different problem as there are no pits into which the caustic red mud can be deposited. Disposal into the ocean has been considered environmentally unacceptable since the 1970s, so improved systems of neutralisation and stabilisation must be sought.

Table 1 Principal environmental concerns related to major mines in the tropical region of Australia's Northern Territory

\begin{tabular}{llll}
\hline Site & Commodity & $\begin{array}{l}\text { Post-Mining Waste } \\
\text { Disposal }\end{array}$ & Principal Risk \\
\hline Rio Tinto Alcan Gove & Bauxite & Surface & Caustic drainage \\
Ranger & Uranium & In-pit & Radiation and metal drainage \\
Rum Jungle & Uranium/copper & Surface & AMD and metal drainage \\
Woodcutters & Silver/lead/zinc & In-pit and surface & AMD and metal drainage \\
Nabarlek & Uranium & In-pit & Radiation and metal drainage \\
GEMCO & Manganese & In-pit & \\
Mount Todd & Gold & Surface & AMD and metal drainage \\
Redbank & Copper & In-pit and surface & AMD and metal drainage \\
McArthur River & Silver/lead/zinc & Surface disposal & AMD and metal drainage \\
Bootu Creek & Manganese & In-pit and surface & \\
\hline
\end{tabular}

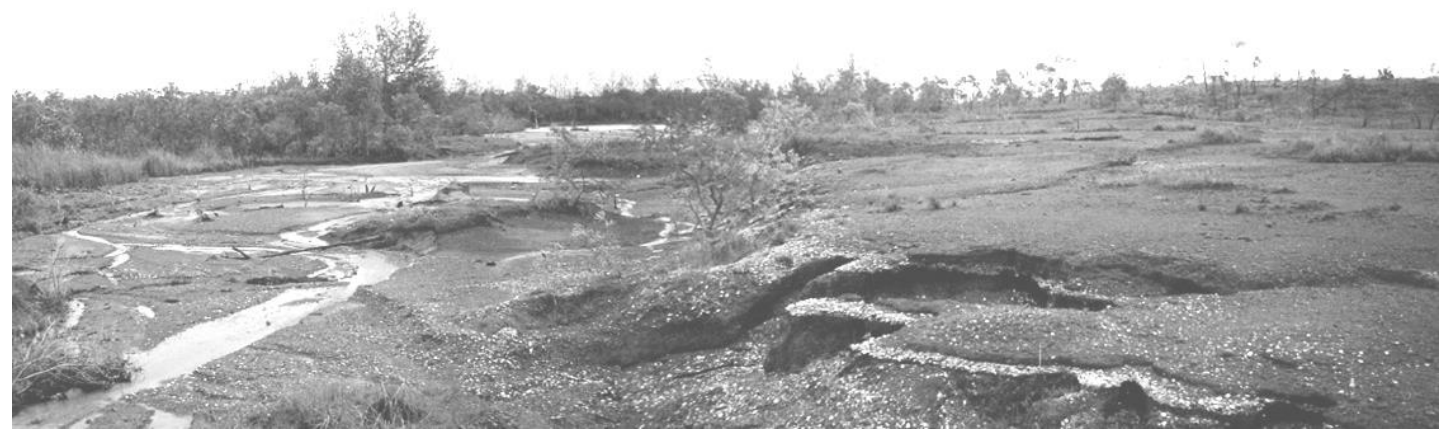

Figure 2 Southern edge of Taylor's Pond at Rio-Tinto Alcan Gove's red mud pond system. Note the underscoring of the poorly vegetated and stabilised surface

\subsection{Water management}

Continued provision of high quality potable water sources is of vital importance to the health and well-being of remote Aboriginal communities and to the natural resources upon which they rely. However, extreme climatic events and high variability of rainfall (Figure 3 and Table 2) make water management another major problems that mining companies in the tropical reaches of the Northern Territory must face. Significant operational problems have occurred at the Ranger Uranium Mine and Rio-Tinto Alcan Gove refinery over the past decade as these companies struggle to cope with high and variable rainfall patterns. Continued acid mine and metalliferous drainage and seepage from surface structures will follow closure unless robust, longterm water management systems designed to protect the environment are implemented. In their absence, detrimental impacts on the environment and underlying health and socio-economic well-being of Aboriginal people will continue to occur.

In pit storage of tailings and waste rock will assist in mitigating the potential for long-term acid mine and metalliferous drainage providing that the acid generating material remains below the level of the water table and oxidation breakdown is prevented. Where this is not done - for example at legacy sites - or at locations 
where treatment of groundwater seepage is required, the long-term challenge remains. Contaminated groundwater may continue to express as springs accessible to both people and fauna in the future, creating an ongoing risk to human health. It is unacceptable to rely solely upon dilution by aquifers or fencing of groundwater seeps to prevent access, but instead active and passive water treatment systems must be engaged.

Sophisticated water treatment systems that utilise reverse osmosis and micro or ultrafiltration are available, but companies may be loathe to use them because of the high costs, volumes of water and length of time involved. Where the construction and use of water treatment technology is deemed to be impractical, consideration must be given to alternative means of water treatment such as anaerobic sentinel wetland systems. These can be constructed using materials that attenuate metalliferous discharge or that partially neutralise acid values. A wide number of alkaline materials including modified red mud have also been considered (Johnston et al., 2010; Maddocks, 2009), but these tend to be costly, not readily available or require on-going maintenance. However the sentinel wetland may be constructed, it may be possible to increase its efficiency by using a specialised group of plants, known as metallophytes.

Table 2 Variability in rainfall recorded at a number of stations in close proximity to major mines in Australia's Northern Territory

\begin{tabular}{llcccc}
\hline Site & Status & $\begin{array}{c}\text { Number of } \\
\text { Records (Period) }\end{array}$ & $\begin{array}{c}\text { Mean } \\
\text { Rainfall } \\
(\mathbf{M m})\end{array}$ & $\begin{array}{c}\text { Minimum } \\
\text { Rainfall } \\
(\mathbf{M m})\end{array}$ & $\begin{array}{c}\text { Maximum } \\
\text { Rainfall } \\
(\mathbf{M m})\end{array}$ \\
\hline $\begin{array}{l}\text { Rio Tinto Alcan }_{\text {Gove }^{1}} \\
\text { Ranger }^{2}\end{array}$ & Operating & $67(1944-2010)$ & 1,474 & 653 & 2,572 \\
Rum Jungle $^{3}$ & Operating & $40(1971-2010)$ & 1,568 & 1,038 & 2,623 \\
Woodcutters $^{3}$ & Closed & $16(1995-2010)$ & 1,538 & 816 & 2,130 \\
Nabarlek $^{4}$ & Closed & $16(1995-2010)$ & 1,538 & 816 & 2,130 \\
GEMCO $^{5}$ & Closed & $101(1910-2010)$ & 1,411 & 776 & 2,203 \\
Mount Todd $^{6}$ & Operating & $31(1970-2010)$ & 1,219 & 627 & 1,946 \\
Redbank $^{7}$ & Closed & $68(1943-2010)$ & 1,139 & 678 & 1,772 \\
McArthur River $^{8}$ & Operating & $35(1966-2010)$ & 992 & 308 & 1,941 \\
Bootu Creek & Operating & $32(1969-2010)$ & 776 & 294 & 1,430 \\
\hline
\end{tabular}

Stations used are: 1 - Gove Airport; 2 - Jabiru; 3 - Batchelor aerodrome; 4 - Oenpelli; 5 - Alyangula; 6 - Katherine; 7 - Wollongorang Station; 8 - McArthur River Mine. 


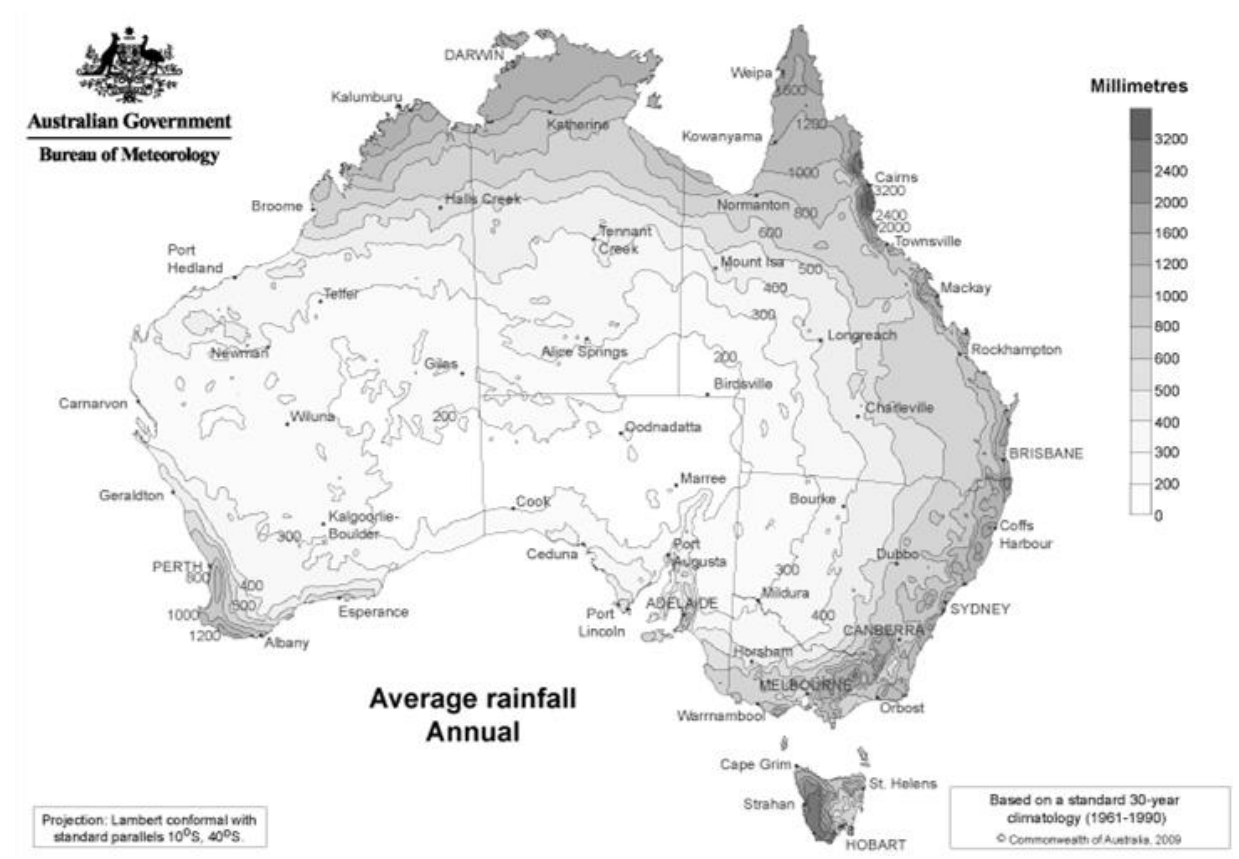

Figure 3 Bureau of meteorology rainfall map for northern Australia

\subsection{A role for metallophytes}

Metallophytes are plants that have the ability to extract metallic species from the environment making them a 'natural resource based technology' considered to be useful for ecological rehabilitation at mine closure. The ability of metallophytes to tolerate extreme metal concentrations also makes them useful for revegetation of mines and metal-contaminated sites by processes known as phytostabilisation and phytoremediation (Whiting et al., 2004).

Metallophytes suitable for the removal of specific chemical species common to acid mine drainage or the surface release of tailings porewater make them potentially useful as adjuncts to water purification through sentinel wetlands and for the stabilisation of backfilled pit surfaces or residual surface structures where backfilling is not possible. For example, halophytes, which have a special affinity for a highly saline environment when used in combination with neutralisation of red mud may lead to improved surface stabilisation and water management systems designed that control erosion and caustic release at Gove.

A large number of metallophytes of potential use as stable vegetative covers or for extraction of metal values from contaminated soils have been catalogued (Pudmenzky et al., 2009). The majority of these are useful for remediation of water and soils contaminated with base metals common to metalliferous drainage (e.g. copper, nickel and zinc), but few useful exotics, capable of dealing with radionuclides have so far been identified. However, special attention needs to be paid to land management practices where metallophytes are used, because if left in a post-closure landscape that is unregulated and unmonitored, the metals concentrated in the metallophytes may be released back into the environment and food chain through natural processes of ashing or decay.

\subsection{The business of land management}

The practice of walking away without providing on-going maintenance once a closure certificate is received has resulted in legacies at a number of mines in tropical Australia - the costs of which are borne by the community. These can take the form of environmental problems (as discussed previously) or socio-economic problems where a dependency on the mine has developed.

Where Aboriginal communities and land are affected, business systems that integrate cultural landscaping, Traditional Ecological Knowledge and mining technology can be used to assist with sustainable land management. This will require collection of a strong set of pre-mining data in a form that can be managed 
and utilised by Aboriginal people. As this knowledge constitutes their intellectual property and may have access restrictions, specific cultural and legal protections need to be built into any database where it is stored.

A preference should be for Aboriginal owned and operated land management business development during mine development and to apply this information at all phases of the mining operation. As many areas of the Northern Territory now have Ranger groups charged with tending to the land, these should be utilised as the main vehicle for environmental management and rehabilitation work at the minesite. If this process is ongoing from the start of the mine, then the groups will develop familiarity with the requirements of the mining company as it heads towards sustainable closure and be in a position to apply their own knowledge in an effective manner.

Training skills related to monitoring of environmental parameters and management of some aspects of mine closure (e.g. management of metallophytes) will need to be developed in conjunction with specific site requirements. Once established however, an on-going and stable business can lead to application of skills elsewhere and assist with socio-economic problems that may arise following closure.

\subsection{Regulating for closure}

Legacy sites lead to high costs to be borne either by the community or the taxpayer. For example, construction of the purpose built facility to contain radioactive tailings in southern Kakadu National Park cost the Australian Federal Government close to $\mathrm{A} \$ 15$ million; a further $\mathrm{A} \$ 8$ million has been directed to inform rehabilitation plans at Rum Jungle and closure at Ranger Uranium Mine is expected to cost upward of A \$ 200 million. Fortunately the Northern Territory Government appears to have learned a valuable lesson following its inability to fully recoup costs associated with closure of the Mount Todd Mine; and has instituted a system where a bond that reflects full closure costs and is revised annually is acquired prior to onset of mining. The most significant downside to the system is that these bonds do not generally reflect a future need for ongoing monitoring, maintenance or land management following closure.

There are two alternatives to consider - the first being refusal to issue a closure certificate until it is proven that stable closure criteria have been met. This is a time intensive process that may not be met in some instances (e.g. revegetation criteria) until several decades after operations have ceased. The second alternative is creation of intergenerational equity trust funds designed to assist businesses charged with management of the post-closure landscape. To be effective, these need to be considered by regulators as an integral part of the rehabilitation and closure bond paid by the companies. Through high costs associated with the longevity of the closure process, it is possible that such funds could also serve as another means to encourage mining companies to develop processes that allow more rapid development of sustainable postmining environment

Difficulties associated with tailings management and higher costs for trusts can be expected at locations like Gove, where in pit tailings and waste rock disposal is not possible. However, it is sites like Gove that will require additional attention and maintenance well into the future just to ensure that the red mud waste dumps remain stable. With intergenerational equity trusts comes a requirement for intergenerational monitoring, so long-term systems of regulation will also be required. This will be costly and challenging to mining companies and governments, but necessary if a sustainable post-mining environment is to be developed.

\section{Conclusions}

A combination of inadequate mine closure systems, heavy rainfall and extreme weather events in tropical regions of Australia's Northern Territory has led to serious environmental problems and significant concern about our ability to development sustainable post-mining landscapes. It has been shown here that reaching the goal of sustainable land management in an environment that has been damaged by mining is both costly and technically challenging. It will require significant input from all sectors of the community if the postclosure landscape is to offer value and intergenerational equity to future generations. This is especially noticeable in the more remote and tropical areas of Australia's Northern Territory where there are significant legacies of old mining practices remain that deplete and continue to contaminate the water supplies and natural resources of many Aboriginal communities. 
With the exception of the possible use of metallophytes for phytostabilisation and phytoextraction of acid mine induced metalliferous contamination, there appears to be little on the horizon by way of innovation to assist with improvement to mine closure practice. There are however, philosophical changes that need to be implemented if the standard of mine closure in the tropical regions of Australia's Northern Territory is to improve. These are site and process specific and require support of strong regulatory and monitoring regimes if they are to be successful.

The basic precepts that constitute the new best practice paradigm offered here are a confluence of land management practices that include:

- Detailed attention to health and cultural considerations into the pre-mining and closure risk management processes.

- Application of traditional knowledge, pre-mining cultural landscaping and baseline socio-economic measures to assist with directing decisions on closure criteria development and end land use.

- Removal of all residual infrastructure with all areas rehabilitated to a standard such that the land has future value and is useable by subsequent generations.

- In pit storage of tailings and potentially acid forming waste rocks in a graded manner such that the most contaminated materials are deepest and the cleanest materials are at the top of the pit.

- Use of pit drainage systems that direct tailings porewater to treatment plans prior to disposal into nearby watercourses.

- Sealing of back-filled pits with impermeable materials and covering with natural vegetation that is not suitable as foods unless they are otherwise proven to be safe to eat.

- Construction of special sentinel wetlands to attenuate chemical species where groundwater seepage occurs.

- Buffering of sentinel wetlands by metallophytic plants for several kilometres downstream to provide a secondary line of defence.

- Provision of adequate capital to ensure that appropriate long-term land management plans are in place.

- Where Aboriginal lands are affected, local Aboriginal Ranger groups should be engaged in environmental management prior to mine development and throughout operations so that their capacity to manage the post-closure environment is maximised.

With refinement of the fundamental philosophy behind mine closure and implementation of the precepts described above, positive impacts on remote area socio-economics and health may be possible - provided there is the support of strong legislation and clear commitments from the mining industry to remove and prevent legacies that are detrimental to the post-closure environment.

\section{References}

ANZEC/MCA (2000) Australian and New Zealand Minerals and Energy Council and the Minerals Council of Australia ANZMEC and MCA: Strategic framework for mine closure http://www.dmp.wa.gov.au/documents/ Shed_env_guide_closure.pdf (2000), accessed 31 March 2011.

DITR (2006) Mine closure and completion. Department of Industry, Tourism and Resources, Commonwealth of Australia. http://www.dmp.wa.gov.au/documents/mine_closure.pdf (2006), accessed 31 March 2011.

Environment Australia (2002) Overview of Best Practice Environmental Management in Mining, Best Practice Environmental Management in Mining Series, Environment Australia, Canberra. http://www.ret.gov.au/ resources/Documents/LPSDP/BPEMOverview.pdf (2002), accessed 31 March 2011.

Johnston, M., Clark, M.W., McMahon, P. and Ward, N. (2010) Alkalinity conversion of bauxite refinery residues by neutralization, Journal of Hazardous Materials, 182, (1-3), pp. 710-715.

Maddocks, G.A. (2009) Reactive in-situ covers for the remediation of mine waste rock using BAUXSOL lime and biosolids, PhD thesis, Southern Cross University, Lismore, NSW. 
Mudd, G.M., Smith, H.D., Kyle, G. and Thompson, A. (2011) In-Pit Tailings - World's Best Practice for Long-Term Management of Tailings, MetPlant 2011: Plant design and operating strategies - world's best practice, Perth, Western Australia, 8-9 August 2011.

Pudmenzky, A., Rossato, L., Doley, D., Ramirez-Bullon, C. and Baker, A.J.M. (2009) Development of a metallophyte spatial database covering Australia. Ecosystem Reconstruction and Pedogenesis. Proceedings Fourth International Conference on Mine Closure (Mine Closure 2009), A.B. Fourie and M. Tibbett (eds), 9-11 September 2009, Perth, Australia, Australian Centre for Geomechanics, Perth, pp. 311-315.

Reszat, T.N., Balding, G. and Fawcett, M. (2009) Remediation of small scale uranium mining activities in the South Alligator Valley, Kakadu National Park. Proceedings Fourth International Conference on Mine Closure (Mine Closure 2009), A.B. Fourie and M. Tibbett (eds), 9-11 September 2009, Perth, Australia, Australian Centre for Geomechanics, Perth, pp. 213-228.

Smith, H.D. (2008) Using Traditional Ecological Knowledge to Develop Closure Criteria in Tropical Australia, Proceedings Third International Seminar on Mine Closure (Mine Closure 2008), A.B. Fourie and M. Tibbett, I.M. Weiersbye, P. Dye (eds), 14-17 October 2008, Johannesburg, South Africa, Australian Centre for Geomechanics, Perth, pp. 47-56.

Smith, H.D. (2009) Strangers in a foreign land - developing cultural closure criteria for mines in Australia's Northern Territory. Proceedings Fourth International Conference on Mine Closure (Mine Closure 2009), A.B. Fourie and M. Tibbett (eds), 9-11 September 2009, Perth, Australia, Australian Centre for Geomechanics, Perth, pp. 3-12.

Whiting, S.N., Reeves, R.D., Richards, D., Johnson, M.S., Cooke, J.A., Malaisse, F., Paton, A., Smith, J.A.C., Angle, J.S., Chaney, R.L., Ginocchio, R., Jaffré, T., Johns, R., McIntyre, T., Purvis, O.W., Salt, D.E., Schat, H., Zhao, F.J. and Baker, A.J.M. (2004) Research Priorities for Conservation of Metallophyte Biodiversity and their Potential for Restoration and Site Remediation, Restoration Ecology, 12, (1), pp. 106-116.

WMI (1994) Whitehorse Mining Initiative. Leadership Council Accord. The Mining Association of Canada. http://www.nrcan.gc.ca/mms-smm/poli-poli/pdf/accord-eng.pdf (1994), accessed 31 March 2011. 
